\title{
Review Article \\ The Role of p38 MAPK in the Aetiopathogenesis of Psoriasis and Psoriatic Arthritis
}

\author{
Athanasios Mavropoulos, ${ }^{1,2}$ Eirini I. Rigopoulou, ${ }^{3}$ Christos Liaskos, ${ }^{1}$ \\ Dimitrios P. Bogdanos, ${ }^{1,2,3}$ and Lazaros I. Sakkas ${ }^{3,4,5}$ \\ ${ }^{1}$ Cellular Immunotherapy and Molecular Immunodiagnostics, Institute of Research and Technology Thessaly, \\ 41222 Larissa, Greece \\ ${ }^{2}$ Division of Transplantation Immunology and Mucosal Biology, Institute of Liver Studies, King's College London School of \\ Medicine at King's College Hospital, Denmark Hill Campus, London SE5 9RS, UK \\ ${ }^{3}$ Department of Medicine, Faculty of Medicine, School of Health Sciences, University of Thessaly, Biopolis, 41110 Larissa, Greece \\ ${ }^{4}$ Center of Molecular Medicine, Old Dominion University, 23529 Monarch Way, Norfolk, VA, USA \\ ${ }^{5}$ Department of Rheumatology, Faculty of Medicine School of Health Sciences, University of Thessaly, Biopolis, 41110 Larissa, Greece
}

Correspondence should be addressed to Lazaros I. Sakkas; lsakkas@med.uth.gr

Received 5 July 2013; Accepted 14 August 2013

Academic Editor: Yehuda Shoenfeld

Copyright (C) 2013 Athanasios Mavropoulos et al. This is an open access article distributed under the Creative Commons Attribution License, which permits unrestricted use, distribution, and reproduction in any medium, provided the original work is properly cited.

The pathogenetic mechanisms responsible for the induction of immune-mediated disorders, such as psoriasis, remain not well characterized. Molecular signaling pathways are not well described in psoriasis, as well as psoriatic arthritis, which is seen in up to $40 \%$ of patients with psoriasis. Signaling pathway defects have long been hypothesized to participate in the pathology of psoriasis, yet their implication in the altered psoriatic gene expression still remains unclear. Emerging data suggest a potential pathogenic role for mitogen activated protein kinases p38 (p38 MAPK) extracellular signal-regulated kinase 1/2 (ERK1/2), and c-Jun N-terminal kinase (JNK) in the development of psoriasis. The data are still limited, though, for psoriatic arthritis. This review discusses the current data suggesting a crucial role for p38 MAPK in the pathogenesis of these disorders.

\section{Introduction}

Psoriasis is a chronic inflammatory skin disease affecting $1-2 \%$ of the population. Clinically, skin lesions are characterized by erythematous plaques covered by scales and pathologically by keratinocyte hyperproliferation and altered differentiation, inflammatory infiltrates, and neovascularization [1-4]. Up to $40 \%$ of patients with psoriasis develop an inflammatory arthritis called psoriatic arthritis (PsA) $[5,6]$.

The mechanisms responsible for skin lesions in psoriasis and the development of PsA remain elusive [7]. Nevertheless, a wealth of data supports the notion that specialized components of the immune system play an important role in the pathogenesis of these disorders [8-10]. Thus, psoriatic patients have elevated levels of circulating neutrophils, and specialized macrophages and dendritic cells appear early in skin lesions followed by activated natural killer cells and
T cells that sustain a loop with distinctive Thl- and Th17mediated pathology [11-17] (Table 1). PsA is also characterized by pronounced $\mathrm{T}$ - and $\mathrm{B}$-cell infiltrates, synovial hyperplasia, and angiogenesis in the synovial membrane, as well as by overexpression of inflammatory cytokines and proteases $[18,19]$.

Cytokines, such as tumor necrosis factor- (TNF)- $\alpha$ and interferon- $\gamma$ (IFN- $\gamma$ ), interleukin- (IL)- $1 \beta$, IL-6, and IL-8, and chemokines, such as CXCL9, CXCL10, CXCL11, and cyclooxygenase-2 (COX-2), are involved in the initiation and perpetuation of psoriatic lesions [33-36]. Th17 cells with their signature cytokine IL-17 are also involved in psoriasis and PsA $[37,38]$. Recently, additional cytokines, namely, IL21, IL-22, IL-23, and IL-27, as well as certain inflammatory biomarkers, have been implicated in psoriatic pathologies [39-45] (Table 1).

The use of cytokine antagonists is an important therapeutic advance in the current management of PsA and 
TABLE 1: Innate and adaptive immunity mediators likely to be involved in psoriasis and psoriatic arthritis.

\begin{tabular}{ll}
\hline Psoriasis & Psoriatic arthritis \\
\hline (i) Prominent lymphocytic & (i) Prominent lymphocytic \\
infiltrate present in skin & infiltrate present in joints \\
\hline (i) TH1, TH17, TH22, NK, & (i) TH1, TH17, TH22, NK?, \\
NKT, B cells & NKT?, B cells \\
(ii) Dendritic cells, & (ii) Dendritic cells, \\
macrophages & macrophages? \\
\hline (i) IL-12, IL-23, TNF-A, IFN- $\gamma$ & (i) IL-12, IL-23, TNF-A, IFN- $\gamma$ \\
\hline (i) IL-6, IL-17A, IL-17F, IL-21, & (i) IL-6, IL-17A, IL-17F, IL-21, \\
IL-22, IL-26, IL-27 & IL-22, IL-26, IL-27 \\
(ii) Cathepsin K, psoriasin & (ii) Cathepsin K?, psoriasin? \\
(iii) Keratin 17 & (iii) Keratin 17? \\
(iv) Plasma YKL-40? & (iv) Plasma YKL-40 \\
(v) Purinergic receptor P2X7 & (v) Purinergic receptor P2X7? \\
(vi) Trem 1 & (vi) Trem 1? \\
\hline (i) MAP kinases ERK1/2, JNK, & (i) MAP kinases ERK1/2, JNK, \\
P38 & P38? \\
(ii) MK2, DUSP-1 MSK-1, & (ii) MK2?, DUSP-1?, MSK-1, \\
GSK-3 $\beta$ & GSK-3 $\beta$ ? \\
(iii) NFKB, JAK/STAT-3, & (iii) NFKB, JAK/STAT-3?, \\
CREB & CREB \\
\hline
\end{tabular}

Question marks indicate inadequate data.

plaque psoriasis, and new studies evaluate the efficacy and safety of new cytokine antagonists in these disorders [46]. The novel IL-23/Th17 axis has attracted much attention with the successful application of ustekinumab, a monoclonal antibody against IL-12 and IL-23, in psoriasis and PsA [47-49]. Some success was also reported with anti-IL-17A and anti-IL-22 agents in animal models of psoriasis [50]. Inhibition of IFN- $\gamma$ expression is of special interest, since IFN- $\gamma$ has been recently shown to enhance IL-22 and IL-23 expressions and subsequently induce Th17 cells in psoriatic lesions. A single intradermal injection of IFN- $\gamma$ can induce an inflammatory state in both nonlesional psoriatic and healthy skin [51-55].

\section{The Role of p38 MAPK in Psoriasis}

Signaling pathway defects have long been hypothesized to participate in the pathology of psoriasis, yet their implication in the altered psoriatic gene expression still remains elusive $[56,57]$. The application of immunohistochemistry and Western blotting techniques has provided some information regarding the signaling cascades in psoriatic skin. These experiments identified mitogen-activated protein kinases p38 (p38 MAPKs), extracellular signal-regulated kinase 1/2 (ERK1/2), and c-Jun N-terminal kinase (JNK) to be involved in the pathogenesis of psoriasis $[20-22,58,59]$ (Table 2). The MAPK kinases constitute an important set of three signaling pathways, namely, p38, ERK1/2, and JNK, which control several important functions within the cell, such as cell proliferation, differentiation, gene expression, and apoptosis [60]. The extensive thickening of the epidermis is indicative of imbalance in the homeostasis between proliferation and apoptosis. Indeed, the expression of various apoptosis-related molecules is increased in the psoriatic hyperproliferative epidermis [61].

Kinase assays further confirmed the increased activation of p38 and demonstrated increased activity of the p38 isoforms $\mathrm{p} 38 \alpha, \mathrm{p} 38 \beta$, and $\mathrm{p} 38 \delta$ in lesional compared to nonlesional psoriatic skin [20]. Phosphorylated p38 was widely detected in lesional psoriatic epidermis and exhibited a distinct nuclear localization indicative of the kinase participation in the induction of active gene expression. Recently, the antimicrobial peptide S100A8, known to be upregulated in lesional psoriatic skin, was found to be regulated by a p38-MAPK-dependent mechanism [29]. Similarly, p38dependent expression was demonstrated for the antimicrobial peptides cathelicidin, human $\beta$-defensin- 2 , human $\beta$ defensin-3, and S100A7 in human keratinocytes [30].

The p38 MAPK signaling pathway is a critical mediator in the regulation of both cellular and humoral autoimmune responses [62]. Usually initiated by cellular stresses, T-cell receptor or inflammatory cytokines, p38 MAPK regulates cytokine gene expression by means of transcriptional and posttranscriptional mechanisms, such as stabilization of mRNA transcripts [63-65]. Defects in p38 MAPK pathway can explain the increased expression of proinflammatory cytokines in several immune-mediated diseases, and several pharmaceutical companies have invested heavily in the development of agents that inhibit p38 MAPK activation [66-68]. An increasing number of novel p38 MAPK inhibitors have been tested in experimental models and clinical trials and have advanced our knowledge on the role of p38 MAPK [69].

Therapeutic inhibition of p38 MAPK pathway is mainly based on the notion that natural-negative-feedback mechanisms exist to guarantee that MAPKs are not activated ad infinitum. In this regard, MAP kinases can themselves induce different types of protein phosphatases called dualspecificity phosphatases (DUSPs). DUSPs dephosphorylate MAP kinases and cease their function [70, 71]. Interestingly, the p38 MAPK-negative-feedback mechanism provided by DUSP1 seems to be impaired in psoriasis since DUSP1 mRNA expression was significantly downregulated in psoriatic skin lesions compared to nonlesional psoriatic skin [26].

MAPKs are activated by phosphorylation of both threonine and tyrosine residues, and in turn they phosphorylate other downstream intracellular kinases and transcription factors. One of the downstream targets of p38 MAPK signaling cascade is MAPK-activated protein kinase 2 (MK2). Increased levels of activated MK2 were found in psoriatic lesions [72]. The activity of MK2 was located in the psoriatic epidermis but not in nonlesional psoriatic skin. Additionally, keratinocytes transfected with MK2-specific small interfering RNA had a significant decrease in the MK2 expression, and subsequently a significant reduction in the protein expression of IFN- $\gamma$, TNF- $\alpha$, IL- 6 , and IL- 8 . The mechanism by which p38 MAPK mediates its regulatory effects through downstream kinases has been studied in cells isolated from mice with deleted MK2 [73]. Particularly interesting characteristics of MK2 knockouts are their increased survival and increased stress resistance upon LPS challenge. These mice are deficient in the LPS-induced biosynthesis of several proinflammatory 
TABLE 2: Evidence for p38 MAPK involvement in psoriasis and psoriatic arthritis.

\begin{tabular}{ll}
\hline Diseases & \\
\hline & (1) p38 MAPK is phosphorylated in lesional psoriatic epidermis \\
(2) Phosphorylated p38 is widely detectable in the keratinocyte nuclei indicative of the kinase strong \\
participation in active gene expression \\
(3) Among the p38 MAPK isoforms, p38alpha, p38beta, and p38delta are detectable in lesional \\
psoriatic skin \\
(4) p38-activated kinases MK-2 and MSK-1 are also phosphorylated in psoriatic lesional skin and \\
regulate the production of proinflammatory cytokines such as TNF- $\alpha$ \\
(5) Dual-specificity phosphatase 1 (DUSP1) is an important negative regulator of p38 MAPK activity \\
DUSP1 mRNA expression is downregulated in psoriatic skin lesions compared with paired samples of \\
nonlesional psoriatic skin \\
(6) p38-MAPK induced Ser727 phosphorylation of STAT-1 and STAT-3 is detected in psoriatic skin \\
(7) p38-MAPK-dependent expression of cathelicidin antimicrobial peptide, human $\beta$-defensin-2, \\
human $\beta$-defensin-3, S100A7, and S100A8 \\
(1) Phosphorylated p38 MAPK is detectable in both lining and sublining synovial area \\
(2) P38 positive cells are also detected in inflammatory infiltrates, in perivascular zones, and in the \\
endothelium \\
(3) IL-36 is upregulated in PsA and RA synovia and leads to IL-6 and IL-8 production by synovial \\
fibroblasts through p38/NFkB activation \\
[27, 28]
\end{tabular}

cytokines regulated by $\mathrm{p} 38$, including TNF- $\alpha$, IFN- $\gamma$, IL- 6 , and IL-1. They survive LPS-induced endotoxic shock due to a reduction of almost $90 \%$ in the secretion of TNF- $\alpha$ [74]. MK2 has been regarded as a key molecule participating in host defense against intracellular bacteria through regulation of both TNF- $\alpha$ and IFN- $\gamma$ production $[75,76]$.

Mitogen- and stress-activated protein kinase 1 (MSK1) is another downstream target of both p38 and ERK1/2 MAPKs which regulates the expression of pro-inflammatory cytokine genes through activation of transcription factors. Western blotting analysis revealed a consistent and significant increase in phosphorylated MSK1 (Ser376) in lesional psoriatic skin $[24,77]$. Cultured human keratinocytes incubated with anisomycin or IL-1beta resulted in the phosphorylation of both p38 MAPK and MSK1 (Ser376), whereas MSK1 (Ser376) phosphorylation was inhibited by preincubation with p38 inhibitors or dimethyl fumarate [78]. In addition, transcription factors, such as cAMP/calcium responsive element binding protein (CREB) associated with cellular proliferation gene expression, are also phosphorylated in psoriatic skin [21]. Activation of CREB through ERK1/2 is directly linked with the expression of TNF- $\alpha$, IL-6, and IL- 8 [79]. These cytokines are also under direct regulation by the p38 pathway as well $[80,81]$. p38 MAPK-induced phosphorylation of STAT-3 and of STAT-1 at serine 727 has also been demonstrated in lesional psoriatic skin $[27,28]$. Thus, keratinocytes in the psoriatic epidermis are characterized not only by abnormal proliferation and apoptosis but also by increased expression of inflammatory cytokines [81]. This seems to be regulated by the same signals arising from the activation of MAPK signaling cascades of p38 and ERK1/2 [20, 23, 82].

\section{The Role of p38 MAPK in PsA}

Information about the involvement of MAPK signaling in the pathogenesis of PsA is very scarce despite the fact that activation of MAPKs, specifically p38 and downstream MK2, has been described in rheumatoid arthritis (RA) synovium and the collagen-induced arthritis model of RA $[67,74]$. Inflammatory cytokines upregulated in psoriasis appear to be involved in the pathogenesis of PsA and other spondyloarthritides as well [41, 83, 84]. For example, the administration of infliximab, an anti-TNF- $\alpha$ agent, to patients with PsA improved patients with active PsA and persistently high serum TNF- $\alpha$ levels [85]. A significant reduction in several proinflammatory and modulatory cytokines has also been noted in psoriatic patients with or without arthritis after treatment with etanercept, another TNF- $\alpha$ inhibitor $[86,87]$. Back in 2000, Danning et al. have linked elevated proinflammatory cytokines with $\mathrm{NF} \kappa \mathrm{B}$ activation in PsA synovium [88]. More recent findings underlined the participation of both MAPK signaling and $\mathrm{NF} \kappa \mathrm{B}$ activation in PsA synovium before and after treatment with etanercept [31] (Table 2). Activated p38 was present in both lining and sublining area of the synovial membrane, and p38 positive cells were detected in inflammatory infiltrates and perivascular zones. Activated ERK was mainly present in the sublining area and mononuclear cell infiltrates, whereas activation of JNK was observed in cells of the lining layer of the synovial membrane [31]. This is of particular interest since epidermal deletion of $\mathrm{c}$-Jun and jun-B proteins also triggers psoriasis and psoriatic arthritis in mice [89]. In addition, IL-36 $\alpha$ is upregulated in PsA and RA synovia and leads to IL- 6 and IL- 8 production by synovial fibroblasts through $\mathrm{p} 38 / \mathrm{NF} \kappa \mathrm{B}$ activation [32].

The synovial membrane of PsA is characterized by Tcell and B-cell infiltrates, synovial hyperplasia, angiogenesis, and overexpression of inflammatory cytokines. A better understanding of these cellular populations their signaling pathways, and associated gene expression is necessary in order to advance our knowledge on the pathogenesis of PsA and to successfully identify novel molecular therapeutic targets. Peripheral blood mononuclear cell (PBMC) analyses 
have also aided in providing gene expression profiles of patients with systemic autoimmune disorders, such as RA, multiple sclerosis, and systemic lupus erythematosus. One of such studies in PBMC of patients with PsA identified a unique gene expression signature with MAPK signaling members being among the genes with reduced levels of expression [90]. One interpretation could be that the reduced mRNA levels of certain MAPK pathway members create an imbalance that favors the development of proinflammatory cells in PsA. However, it should be noted that the activation status of MAPK pathway is regulated at the posttranslational level. There was also reduced expression of B-cell specific genes including those of cell activation and T-cell activation genes. These observations from peripheral blood need to be considered with caution in relation to infiltrating lymphocytes from psoriatic skin biopsies [91, 92]. Studies of skin biopsies have identified several upregulated proinflammatory genes including IL-1, IL-6, and IL-8.

Yet, peripheral blood signature studies are of great importance and can provide a lot of information regarding new immune regulatory molecules [93]. For instance, we have optimized a PB flow cytometry-based assay that details cellular phenotypic status, signaling status, and gene expression analysis, all combined [94]. Applications of optimized protocols based on sensitive phospho flow cytometry have been recognised as promising alternatives for the investigation of the phosphorylation of p38 MAPK within different PBMC populations $[95,96]$. Flow cytometry has been so far useful in revealing the phenotype of psoriatic lesion infiltrating cells and their secreted cytokines [11, 97]. However, there has been no information on the kinases and signaling pathways activated in the rare NK and NKT cells of PsA patients. We have previously shown that p38 MAPK regulates posttranscriptional IFN $-\gamma$ gene expression in human NK and NKT cells [63]. This possibly occurs via an MKK6/p38/MK2dependent mechanism for the stabilization of IFN- $\gamma$ mRNA in NK and NKT cells and may play an important role in host defense as well. We have optimized the methodology for the successful application of phospho-specific flow cytometry in order to detect phosphorylated p38 MAPK within innate immune cells, such as NK and NKT $[94,98]$. Because of the critical and bidirectional role of IFN- $\gamma$ in inflammation and autoimmunity, the elucidation of the molecular mechanisms controlling its expression is the focus of ongoing research by our team [62].

As mentioned previously, NK and NKT cells appear as key players in the pathogenesis of psoriasis $[12,99,100]$. In fact, these cells play a significant role in regulating a number of autoimmune skin disorders [101, 102]. Decreased numbers of CD56+ cells have been detected in PB of patients with psoriasis, and impaired function has been documented in other autoimmune diseases, such as primary biliary cirrhosis, multiple sclerosis, systemic lupus erythematosus, RA, and type I diabetes [103-107]. Alterations in killer inhibitory receptors (KIRs) repertoire expression on NK cells and on $\mathrm{T}$ cells have also been associated with several autoimmune diseases including multiple sclerosis, type I diabetes, and psoriasis [108-110]. There is a significant depletion of PB NK and NKT numbers in psoriatic patients that is probably due to an increased accumulation of activated NK and T cells bearing NK-associated receptors in psoriatic lesions [103]. The assessment of MAPK expression levels in cell subpopulations from psoriatic patients would be very informative.

Lesional T cells analyzed by flow cytometry express certain classical NK phenotypic markers, such as CD56, CD16, and CD94, and there is a significant positive correlation between circulating CD8+ CD94/NKG2A $+\mathrm{T}$ cells and the severity index of the psoriatic skin lesions [11, 111]. Patterns of CD1d expression are also observed in keratinocytes in vitro and in human skin with psoriasis in vivo [99]. NKT cells can become activated in a CD1d-restricted fashion with subsequent proliferation and cytokine production, including IFN- $\gamma$ and IL-4. The ability of CD1d-positive keratinocytes to activate NKT cells to produce IFN- $\gamma$ could represent a mechanism that contributes to the pathogenesis of PsA, psoriasis, and other autoimmune skin disorders.

In conclusion, current data suggest that p38 MAPK plays a role in the pathogenesis of psoriasis. However, more studies are needed to further advance this interesting topic of research. At present, the information regarding p38 MAPK involvement in the pathogenesis of PsA is limited and by no means conclusive.

\section{Abbreviations}

DUSP: Dual-specificity phosphatase

IL: Interleukin

MAPK: Mitogen-activated protein kinase

NK: Natural killer

NKT: NK T cells

PsA: Psoriatic arthritis

RA: Rheumatoid arthritis

TNF: Tumor necrosis factor.

\section{References}

[1] M. A. Lowes, A. M. Bowcock, and J. G. Krueger, "Pathogenesis and therapy of psoriasis," Nature, vol. 445, no. 7130, pp. 866-873, 2007.

[2] F. O. Nestle, D. H. Kaplan, and J. Barker, "Mechanisms of disease: psoriasis," New England Journal of Medicine, vol. 361, no. 5, pp. 444-509, 2009.

[3] G. Krueger and C. N. Ellis, "Psoriasis-recent advances in understanding its pathogenesis and treatment," Journal of the American Academy of Dermatology, vol. 53, no. 1, supplement, pp. S94-S100, 2005.

[4] J. D. Bos, M. A. De Rie, M. B. M. Teunissen, and G. Piskin, "Psoriasis: dysregulation of innate immunity," British Journal of Dermatology, vol. 152, no. 6, pp. 1098-1107, 2005.

[5] D. D. Gladman, C. Antoni, P. Mease, D. O. Clegg, and O. Nash, "Psoriatic arthritis: epidemiology, clinical features, course, and outcome," Annals of the Rheumatic Diseases, vol. 64, no. 2, pp. ii14-iil7, 2005.

[6] W. H. Boehncke and A. Menter, "Burden of disease: psoriasis and psoriatic arthritis," American Journal of Clinical Dermatology, 2013.

[7] R. K. H. Mak, C. Hundhausen, and F. O. Nestle, "Progress in understanding the immunopathogenesis of psoriasis," Actas Dermo-Sifiliograficas, vol. 100, no. 2, pp. 2-13, 2009. 
[8] D. J. Veale, C. Ritchlin, and O. FitzGerald, "Immunopathology of psoriasis and psoriatic arthritis," Annals of the Rheumatic Diseases, vol. 64, no. 2, supplement, pp. ii26-ii29, 2005.

[9] H. Bachelez, "Immunopathogenesis of psoriasis: recent insights on the role of adaptive and innate immunity," Journal of Autoimmunity, vol. 25, supplement, pp. 69-73, 2005.

[10] F. Villanova, P. Di Meglio, and F. O. Nestle, "Biomarkers in psoriasis and psoriatic arthritis," Annals of the Rheumatic Diseases, vol. 72, supplement 2, pp. 104-110, 2013.

[11] C. Ottaviani, F. Nasorri, C. Bedini, O. de Pità, G. Girolomoni, and A. Cavani, "CD56brightCD16- NK cells accumulate in psoriatic skin in response to CXCL10 and CCL5 and exacerbate skin inflammation," European Journal of Immunology, vol. 36, no. 1, pp. 118-128, 2006.

[12] S. Peternel and M. Kaštelan, "Immunopathogenesis of psoriasis: focus on natural killer T cells," Journal of the European Academy of Dermatology and Venereology, vol. 23, no. 10, pp. 1123-1127, 2009.

[13] S. Kagami, H. L. Rizzo, J. J. Lee, Y. Koguchi, and A. Blauvelt, "Circulating Th17, Th22, and Th1 cells are increased in psoriasis," Journal of Investigative Dermatology, vol. 130, no. 5, pp. 13731383, 2010.

[14] J. Fuentes-Duculan, M. Suárez-Farĩas, L. C. Zaba et al., "A subpopulation of CD163-positive macrophages is classically activated in psoriasis," Journal of Investigative Dermatology, vol. 130, no. 10, pp. 2412-2422, 2010.

[15] A. M. Tobin, L. Lynch, B. Kirby, and C. O’Farrelly, "Natural killer cells in psoriasis," Journal of Innate Immunity, vol. 3, no. 4, pp. 403-410, 2011.

[16] A. Farkas and L. Kemeny, "Monocyte-derived interferon-alpha primed dendritic cells in the pathogenesis of psoriasis: new pieces in the puzzle," International Immunopharmacology, vol. 13, no. 2, pp. 215-218, 2012.

[17] B. J. Lewis, S. Rajpara, A. M. Haggart, H. M. Wilson, R. N. Barker, and A. D. Ormerod, "Predominance of activated, clonally expanded $\mathrm{T}$ helper type 17 cells within the $\mathrm{CD} 4^{+} \mathrm{T}$ cell population in psoriatic lesions," Clinical \& Experimental Immunology, vol. 173, no. 1, pp. 38-46, 2013.

[18] T. T. Leong, U. Fearon, and D. J. Veale, "Angiogenesis in psoriasis and psoriatic arthritis: clues to disease pathogenesis," Current Rheumatology Reports, vol. 7, no. 4, pp. 325-329, 2005.

[19] S. Maeda, Y. Hayami, T. Naniwa, and R. Ueda, "The Th17/IL-23 axis and natural immunity in psoriatic arthritis," International Journal of Rheumatology, vol. 2012, Article ID 539683, 8 pages, 2012.

[20] C. Johansen, K. Kragballe, M. Westergaard, J. Henningsen, K. Kristiansen, and L. Iversen, "The mitogen-activated protein kinases p38 and ERK1/2 are increased in lesional psoriatic skin," British Journal of Dermatology, vol. 152, no. 1, pp. 37-42, 2005.

[21] X.-J. Yu, C.-Y. Li, H.-Y. Dai et al., "Expression and localization of the activated mitogen-activated protein kinase in lesional psoriatic skin," Experimental and Molecular Pathology, vol. 83, no. 3, pp. 413-418, 2007.

[22] S. Wang, H. Uchi, S. Hayashida, K. Urabe, Y. Moroi, and M. Furue, "Differential expression of phosphorylated extracellular signal-regulated kinase $1 / 2$, phosphorylated p38 mitogenactivated protein kinase and nuclear factor $-\kappa \mathrm{B}$ p105/p50 in chronic inflammatory skin diseases," Journal of Dermatology, vol. 36, no. 10, pp. 534-540, 2009.

[23] J. S. C. Arthur and J. Darragh, "Signaling downstream of p38 in psoriasis," Journal of Investigative Dermatology, vol. 126, no. 8, pp. 1689-1691, 2006.
[24] L. Soegaard-Madsen, C. Johansen, L. Iversen, and K. Kragballe, "Adalimumab therapy rapidly inhibits p38 mitogen-activated protein kinase activity in lesional psoriatic skin preceding clinical improvement," British Journal of Dermatology, vol. 162, no. 6, pp. 1216-1223, 2010.

[25] A. T. Funding, C. Johansen, K. Kragballe et al., "Mitogen- and stress-activated protein kinase 1 is activated in lesional psoriatic epidermis and regulates the expression of pro-inflammatory cytokines," Journal of Investigative Dermatology, vol. 126, no. 8, pp. 1784-1791, 2006.

[26] R. B. Kjellerup, C. Johansen, K. Kragballe, and L. Iversen, "The expression of dual-specificity phosphatase $1 \mathrm{mRNA}$ is downregulated in lesional psoriatic skin," British Journal of Dermatology, vol. 168, no. 2, pp. 339-345, 2013.

[27] R. M. Andres, A. Hald, C. Johansen, K. Kragballe, and L. Iversen, "Studies of Jak/STAT3 expression and signalling in psoriasis identifies STAT3-Ser727 phosphorylation as a modulator of transcriptional activity," Experimental Dermatology, vol. 22, no. 5, pp. 323-328, 2013.

[28] A. Hald, R. M. Andres, M. L. Salskov-Iversen, R. B. Kjellerup, L. Iversen, and C. Johansen, "STAT1 expression and activation is increased in lesional psoriatic skin," British Journal of Dermatology, vol. 168, no. 2, pp. 302-310, 2013.

[29] M. Mose, Z. Kang, L. Raaby, L. Iversen, and C. Johansen, "TNFalpha- and IL-17A-mediated S100A8 expression is regulated by p38 MAPK," Experimental Dermatology, vol. 22, no. 7, pp. 476-481, 2013.

[30] C. S. Hau, N. Kanda, S. Noda et al., "Visfatin enhances the production of cathelicidin antimicrobial peptide, human betadefensin-2, human beta-defensin-3, and S100A7 in human keratinocytes and their orthologs in murine imiquimod-induced psoriatic skin," American Journal of Pathology, vol. 182, no. 5, pp. 1705-1717, 2013.

[31] R. J. U. Lories, I. Derese, F. P. Luyten, and K. de Vlam, "Activation of nuclear factor kappa B and mitogen activated protein kinases in psoriatic arthritis before and after etanercept treatment," Clinical and Experimental Rheumatology, vol. 26, no. 1, pp. 96102, 2008.

[32] S. Frey, A. Derer, M. E. Messbacher et al., "The novel cytokine interleukin-36alpha is expressed in psoriatic and rheumatoid arthritis synovium," Annals of the Rheumatic Diseases, 2013.

[33] N. Kanda, T. Shimizu, Y. Tada, and S. Watanabe, "IL-18 enhances IFN- $\gamma$-induced production of CXCL9, CXCL10, and CXCL11 in human keratinocytes," European Journal of Immunology, vol. 37, no. 2, pp. 338-350, 2007.

[34] A. Michalak-Stoma, A. Pietrzak, J. C. Szepietowski, A. Zalewska-Janowska, T. Paszkowski, and G. Chodorowska, "Cytokine network in psoriasis revisited," European Cytokine Network, vol. 22, no. 4, pp. 160-168, 2011.

[35] E. Retser, T. Schied, B. V. Skryabin et al., "Inducible expression of transgenic human TNFalpha in adult mice develops psoriatic-like arthritis," Arthritis \& Rheumatism, 2013.

[36] D. Hijnen, E. F. Knol, Y. Y. Gent et al., "CD8 ${ }^{+}$T cells in the lesional skin of atopic dermatitis and psoriasis patients are an important source of IFN-gamma, IL-13, IL-17, and IL-22," Journal of Investigative Dermatology, vol. 133, no. 4, pp. 973-979, 2013.

[37] S. P. Raychaudhuri, "Role of IL-17 in psoriasis and psoriatic arthritis," Clinical Reviews in Allergy \& Immunology, vol. 44, no. 2, pp. 183-193, 2013.

[38] D. A. Martin, J. E. Towne, G. Kricorian et al., "The emerging role of IL-17 in the pathogenesis of psoriasis: preclinical and clinical 
findings," Journal of Investigative Dermatology, vol. 133, no. 1, pp. 17-26, 2013.

[39] A. B. Van Belle, M. De Heusch, M. M. Lemaire et al., "IL-22 is required for imiquimod-induced psoriasiform skin inflammation in mice," Journal of Immunology, vol. 188, no. 1, pp. 462-469, 2012.

[40] E. Botti, G. Spallone, R. Caruso, G. Monteleone, S. Chimenti, and A. Costanzo, "Psoriasis, from pathogenesis to therapeutic strategies: IL-21 as a novel potential therapeutic target," Current Pharmaceutical Biotechnology, vol. 13, no. 10, pp. 1861-1867, 2012.

[41] A. Cauli and A. Mathieu, "Th17 and interleukin 23 in the pathogenesis of psoriatic arthritis and spondyloarthritis," Journal of Rheumatology, vol. 89, pp. 15-18, 2012.

[42] S. Shibata, Y. Tada, Y. Asano et al., "IL-27 activates Th1-mediated responses in imiquimod-induced psoriasis-like skin lesions," Journal of Investigative Dermatology, vol. 133, no. 2, pp. 479-488, 2013.

[43] P. Jensen, C. Wiell, K. Milting et al., "Plasma YKL-40: a potential biomarker for psoriatic arthritis?" Journal of the European Academy of Dermatology, vol. 27, no. 7, pp. 815-819, 2013.

[44] L. Jin and G. Wang, "Keratin 17: a critical player in the pathogenesis of psoriasis," Medicinal Research Reviews, 2013.

[45] L. A. Hyder, J. Gonzalez, J. L. Harden et al., "TREM-1 as a potential therapeutic target in psoriasis," Journal of Investigative Dermatology, vol. 133, no. 7, pp. 1742-1751, 2013.

[46] A. Mitra, R. S. Fallen, and H. C. Lima, "Cytokine-based therapy in psoriasis," Clinical Reviews in Allergy \& Immunology, vol. 44, no. 2, pp. 173-182, 2013.

[47] P. M. Laws and R. B. Warren, "Ustekinumab for the treatment of psoriasis," Expert Review of Clinical Immunology, vol. 7, no. 2, pp. 155-164, 2011.

[48] A. Di Cesare, P. Di Meglio, and F. O. Nestle, "The IL-23Th17 axis in the immunopathogenesis of psoriasis," Journal of Investigative Dermatology, vol. 129, no. 6, pp. 1339-1350, 2009.

[49] K. Tsuda, K. Yamanaka, M. Kondo et al., "Ustekinumab improves psoriasis without altering $\mathrm{T}$ cell cytokine production, differentiation, and T cell receptor repertoire diversity," PLoS ONE, vol. 7, no. 12, Article ID e51819, 2012.

[50] E. Y. Gan, W. S. Chong, and H. L. Tey, “Therapeutic strategies in psoriasis patients with psoriatic arthritis: focus on new agents," BioDrugs, 2013.

[51] G. Piskin, U. Tursen, R. M. R. Sylva-Steenland, J. D. Bos, and M. B. M. Teunissen, "Clinical improvement in chronic plaque-type psoriasis lesions after narrow-band UVB therapy is accompanied by a decrease in the expression of IFN- $\gamma$ inducers - IL-12, IL-18 and IL-23," Experimental Dermatology, vol. 13, no. 12, pp. 764-772, 2004.

[52] B. Skurkovich and S. Skurkovich, "Inhibition of IFN-gamma as a method of treatment of various autoimmune diseases, including skin diseases," in Proceedings of the Ernst Schering Research Foundation Workshop, vol. 56, pp. 1-27, 2006.

[53] L. M. Johnson-Huang, M. Suárez-Fariñas, K. C. Pierson et al., "A single intradermal injection of IFN- $\gamma$ induces an inflammatory state in both non-lesional psoriatic and healthy skin," Journal of Investigative Dermatology, vol. 132, no. 4, pp. 1177-1187, 2012.

[54] J. Behrends, J. C. Renauld, S. Ehlers, and C. Holscher, "IL-22 is mainly produced by IFNgamma-secreting cells but is dispensable for host protection against Mycobacterium tuberculosis infection," PLoS ONE, vol. 8, no. 2, Article ID e57379, 2013.

[55] P. Di Meglio and J. H. Duarte, "CD8 T Cells and IFN-gamma emerge as critical players for psoriasis in a novel model of mouse psoriasiform skin inflammation," Journal of Investigative Dermatology, vol. 133, no. 4, pp. 871-874, 2013.

[56] R. C. McKenzie, E. Sabin, J. C. Szepietowski, J. A. Gracie, R. J. Forsey, and S. Howie, "Letter to the editor," European Journal of Dermatology, vol. 13, no. 3, pp. 315-316, 2003.

[57] R. C. McKenzie and E. Sabin, "Aberrant signalling and transcription factor activation as an explanation for the defective growth control and differentiation of keratinocytes in psoriasis: a hypothesis," Experimental Dermatology, vol. 12, no. 4, pp. 337$345,2003$.

[58] I. Haase, R. M. Hobbs, M. R. Romero, S. Broad, and F. M. Watt, "A role for mitogen-activated protein kinase activation by integrins in the pathogenesis of psoriasis," Journal of Clinical Investigation, vol. 108, no. 4, pp. 527-536, 2001.

[59] H. Takahashi, M. Ibe, S. Nakamura, A. Ishida-Yamamoto, Y. Hashimoto, and H. Iizuka, "Extracellular regulated kinase and c-Jun N-terminal kinase are activated in psoriatic involved epidermis," Journal of Dermatological Science, vol. 30, no. 2, pp. 94-99, 2002.

[60] J. M. Kyriakis and J. Avruch, "Mammalian MAPK signal transduction pathways activated by stress and inflammation: a 10 -year update," Physiological Reviews, vol. 92, no. 2, pp. 689737, 2012.

[61] H. Takahashi, A. Manabe, A. Ishida-Yamamoto, Y. Hashimoto, and H. Iizuka, "Aberrant expression of apoptosis-related molecules in psoriatic epidermis," Journal of Dermatological Science, vol. 28, no. 3, pp. 187-197, 2002.

[62] A. Mavropoulos, T. Orfanidou, C. Liaskos et al., "p38 mitogenactivated protein kinase (p38 MAPK)-mediated autoimmunity: lessons to learn from ANCA vasculitis and pemphigus vulgaris," Autoimmunity Reviews, 2012.

[63] A. Mavropoulos, G. Sully, A. P. Cope, and A. R. Clark, "Stabilization of IFN- $\gamma$ mRNA by MAPK p38 in IL-12- and IL-18stimulated human NK cells," Blood, vol. 105, no. 1, pp. 282-288, 2005.

[64] P. Anderson, K. Phillips, G. Stoecklin, and N. Kedersha, "Posttranscriptional regulation of proinflammatory proteins," Journal of Leukocyte Biology, vol. 76, no. 1, pp. 42-47, 2004.

[65] M. Brook, G. Sully, A. R. Clark, and J. Saklatvala, "Regulation of tumour necrosis factor $\alpha$ mRNA stability by the mitogenactivated protein kinase p38 signalling cascade," FEBS Letters, vol. 483, no. 1, pp. 57-61, 2000.

[66] J. Saklatvala, "The p38 MAP kinase pathway as a therapeutic target in inflammatory disease," Current Opinion in Pharmacology, vol. 4, no. 4, pp. 372-377, 2004.

[67] G. Schett, J. Zwerina, and G. Firestein, "The p38 mitogenactivated protein kinase (MAPK) pathway in rheumatoid arthritis," Annals of the Rheumatic Diseases, vol. 67, no. 7, pp. 909-916, 2008.

[68] S. E. Sweeney, "The as-yet unfulfilled promise of p38 MAPK inhibitors," Nature Reviews, vol. 5, no. 9, pp. 475-477, 2009.

[69] L. R. Coulthard, D. E. White, D. L. Jones, M. F. McDermott, and S. A. Burchill, "p38MAPK: stress responses from molecular mechanisms to therapeutics," Trends in Molecular Medicine, vol. 15, no. 8, pp. 369-379, 2009.

[70] S. M. Abraham and A. R. Clark, "Dual-specificity phosphatase 1: a critical regulator of innate immune responses," Biochemical Society Transactions, vol. 34, no. 6, pp. 1018-1023, 2006.

[71] A. R. Clark, "MAP kinase phosphatase 1: a novel mediator of biological effects of glucocorticoids?" Journal of Endocrinology, vol. 178, no. 1, pp. 5-12, 2003. 
[72] C. Johansen, A. T. Funding, K. Otkjaer et al., "Protein expression of TNF- $\alpha$ in psoriatic skin is regulated at a posttranscriptional level by MAPK-activated protein kinase 2," Journal of Immunology, vol. 176, no. 3, pp. 1431-1438, 2006.

[73] A. Kotlyarov, A. Neininger, C. Schubert et al., "MAPKAP kinase 2 is essential for LPS-induced TNF- $\alpha$ biosynthesis," Nature Cell Biology, vol. 1, no. 2, pp. 94-97, 1999.

[74] M. Hegen, M. Gaestel, C. L. Nickerson-Nutter, L.-L. Lin, and J.-B. Telliez, "MAPKAP kinase 2-deficient mice are resistant to collagen-induced arthritis," Journal of Immunology, vol. 177, no. 3, pp. 1913-1917, 2006.

[75] S. Duraisamy, M. Bajpai, U. Bughani, S. G. Dastidar, A. Ray, and P. Chopra, "MK2: a novel molecular target for antiinflammatory therapy," Expert Opinion on Therapeutic Targets, vol. 12, no. 8, pp. 921-936, 2008.

[76] M. Gaestel, A. Kotlyarov, and M. Kracht, "Targeting innate immunity protein kinase signalling in inflammation," Nature Reviews Drug Discovery, vol. 8, no. 6, pp. 480-499, 2009.

[77] A. T. Funding, C. Johansen, K. Kragballe, and L. Iversen, "Mitogen- and stress-activated protein kinase 2 and cyclic AMP response element binding protein are activated in lesional psoriatic epidermis," Journal of Investigative Dermatology, vol. 127, no. 8, pp. 2012-2019, 2007.

[78] B. Gesser, C. Johansen, M. K. Rasmussen et al., "Dimethylfumarate specifically inhibits the Mitogen and Stress-Activated Kinases 1 and 2 (MSK1/2): possible role for its anti-psoriatic effect," Journal of Investigative Dermatology, vol. 127, no. 9, pp. 2129-2137, 2007.

[79] N. Ikewaki and H. Inoko, "A very late activating antigen- $\alpha 4$ (CD49d) monoclonal antibody, BU49 induces phosphorylation of a cAMP response element-binding protein (CREB), resulting in induction of homotypic cell aggregation and enhancement of interleukin-8 (IL-8) production," Microbiology and Immunology, vol. 46, no. 10, pp. 685-695, 2002.

[80] N. Dauletbaev, D. Eklove, N. Mawji et al., "Down-regulation of cytokine-induced interleukin- 8 requires inhibition of $\mathrm{p} 38$ Mitogen-activated Protein Kinase (MAPK) via MAPK phosphatase 1-dependent and -independent mechanisms," Journal of Biological Chemistry, vol. 286, no. 18, pp. 15998-16007, 2011.

[81] C. Johansen, H. Vinter, L. Soegaard-Madsen et al., "Preferential inhibition of the mRNA expression of p38 mitogen-activated protein kinase regulated cytokines in psoriatic skin by antiTNF $\alpha$ therapy," British Journal of Dermatology, vol. 163, no. 6, pp. 1194-1204, 2010.

[82] Z. Guan, S. Y. Buckman, A. P. Pentland, D. J. Templeton, and A. R. Morrison, "Induction of cyclooxygenase-2 by the activated MEKK1 $\rightarrow$ SEK1/MKK4 $\rightarrow$ p38 mitogen-activated protein kinase pathway," Journal of Biological Chemistry, vol. 273, no. 21, pp. 12901-12908, 1998.

[83] R. Celis, N. Planell, J. L. Fernandez-Sueiro et al., "Synovial cytokine expression in psoriatic arthritis and associations with lymphoid neogenesis and clinical features," Arthritis Research \& Therapy, p. R93, 2012.

[84] L. Candia, J. Marquez, C. Hernandez, A. H. Zea, and L. R. Espinoza, "Toll-like receptor-2 expression is upregulated in antigen-presenting cells from patients with psoriatic arthritis: a pathogenic role for innate immunity?" Journal of Rheumatology, vol. 34, no. 2, pp. 374-379, 2007.

[85] H. Amital, V. Barak, R. E. Winkler, and A. Rubinow, "Impact of treatment with infliximab on serum cytokine profile of patients with rheumatoid and psoriatic arthritis," Annals of the New York Academy of Sciences, vol. 1110, pp. 649-660, 2007.
[86] P. Cordiali-Fei, M. Ardigò, A. Mastroianni et al., "Serum cytokines and bioumoral immunological characterization of psoriatic patients in long term etanercept treatment," International Journal of Immunopathology and Pharmacology, vol. 21, no. 3, pp. 643-649, 2008.

[87] K. de Vlam and R. J. U. Lories, "Efficacy, effectiveness and safety of etanercept in monotherapy for refractory psoriatic arthritis: a 26-week observational study," Rheumatology, vol. 45, no. 3, pp. 321-324, 2006.

[88] C. L. Danning, G. G. Illei, C. Hitchon, M. R. Greer, D. T. Boumpas, and I. B. McInnes, "Macrophage-derived cytokine and nuclear factor kappaB p65 expression in synovial membrane and skin of patients with psoriatic arthritis," Arthritis \& Rheumatism, vol. 43, no. 6, pp. 1244-1256, 2000.

[89] R. Zenz, R. Eferl, L. Kenner et al., "Psoriasis-like skin disease and arthritis caused by inducible epidermal deletion of Jun proteins," Nature, vol. 437, no. 7057, pp. 369-375, 2005.

[90] F. M. Batliwalla, W. Li, C. T. Ritchlin et al., "Microarray analyses of peripheral blood cells identifies unique gene expression signature in psoriatic arthritis," Molecular Medicine, vol. 11, no. 1-12, pp. 21-29, 2005.

[91] A. M. Bowcock, W. Shannon, F. Du et al., "Insights into psoriasis and other inflammatory diseases from large-scale gene expression studies," Human Molecular Genetics, vol. 10, no. 17, pp. 1793-1805, 2001.

[92] V. Quekenborn-Trinquet, P. Fogel, O. Aldana-Jammayrac et al., "Gene expression profiles in psoriasis: analysis of impact of body site location and clinical severity," British Journal of Dermatology, vol. 152, no. 3, pp. 489-504, 2005.

[93] D. Koczan, R. Guthke, H.-J. Thiesen et al., "Gene expression profiling of peripheral blood mononuclear leukocytes from psoriasis patients identifies new immune regulatory molecules," European Journal of Dermatology, vol. 15, no. 4, pp. 251-257, 2005.

[94] A. Mavropoulos, D. Smyk, E. I. Rigopoulou, and D. P. Bogdanos, "Human peripheral blood mononuclear cell culture for flow cytometric analysis of phosphorylated mitogen-activated protein kinases," Methods in Molecular Biology, vol. 806, pp. 275285, 2012.

[95] P. O. Krutzik, J. M. Irish, G. P. Nolan, and O. D. Perez, "Analysis of protein phosphorylation and cellular signaling events by flow cytometry: techniques and clinical applications," Clinical Immunology, vol. 110, no. 3, pp. 206-221, 2004.

[96] D. T. Montag and M. T. Lotze, "Rapid flow cytometric measurement of cytokine-induced phosphorylation pathways [CIPP] in human peripheral blood leukocytes," Clinical Immunology, vol. 121, no. 2, pp. 215-226, 2006.

[97] S. Abecassis, J. Giustiniani, N. Meyer et al., "Identification of a novel $\mathrm{CD} 160^{+} \mathrm{CD} 4^{+} \mathrm{T}$-lymphocyte subset in the skin: a possible role for CD160 in skin inflammation," Journal of Investigative Dermatology, vol. 127, no. 5, pp. 1161-1166, 2007.

[98] A. Mavropoulos, E. Spyrou, E. I. Rigopoulou, D. Vergani, G. N. Dalekos, and D. P. Bogdanos, "1107 Phosphorylation of P38 MAPK is detectable in NKT cells of patients with autoimmune hepatitis in whom it mirrors disease activity," Journal of Hepatology, vol. 52, p. S428, 2010.

[99] B. Bonish, D. Jullien, Y. Dutronc et al., "Overexpression of CD1d by keratinocytes in psoriasis and CD1d-dependent IFN- $\gamma$ production by NK-T cells," Journal of Immunology, vol. 165, no. 7, pp. 4076-4085, 2000. 
[100] A. Cameron, B. Kirby, W. Fei, and C. Griffiths, "Natural killer and natural killer-T cells in psoriasis," Archives of Dermatological Research, vol. 294, no. 8, pp. 363-369, 2002.

[101] D. von Bubnoff, E. Andrès, F. Hentges, T. Bieber, T. Michel, and J. Zimmer, "Natural killer cells in atopic and autoimmune diseases of the skin," Journal of Allergy and Clinical Immunology, vol. 125, no. 1-3, pp. 60-68, 2010.

[102] L. R. Zakka, E. Fradkov, D. B. Keskin, I. Tabansky, J. N. H. Stern, and A. R. Ahmed, "The role of natural killer cells in autoimmune blistering diseases," Autoimmunity, vol. 45, no. 1, pp. 44-54, 2012.

[103] A. L. Cameron, B. Kirby, and C. E. M. Griffiths, "Circulating natural killer cells in psoriasis," British Journal of Dermatology, vol. 149, no. 1, pp. 160-164, 2003.

[104] S. Johansson, H. Hall, L. Berg, and P. Hoglund, "NK cells in autoimmune disease," Current Topics in Microbiology and Immunology, vol. 298, pp. 259-277, 2006.

[105] C. Selmi, A. Lleo, S. Pasini, M. Zuin, and M. E. Gershwin, "Innate immunity and primary biliary cirrhosis," Current Molecular Medicine, vol. 9, no. 1, pp. 45-51, 2009.

[106] C. Åkesson, K. Uvebrant, C. Oderup et al., "Altered natural killer (NK) cell frequency and phenotype in latent autoimmune diabetes in adults (LADA) prior to insulin deficiency," Clinical and Experimental Immunology, vol. 161, no. 1, pp. 48-56, 2010.

[107] B. Hervier, V. Beziat, J. Haroche et al., "Phenotype and function of natural killer cells in systemic lupus erythematosus: excess interferon- $\gamma$ production in patients with active disease," Arthritis \& Rheumatism, vol. 63, no. 6, pp. 1698-1706, 2011.

[108] Y. H. Liao, S. H. Jee, B. C. Sheu et al., "Increased expression of the natural killer cell inhibitory receptor CD94/NKG2A and $\mathrm{CD} 158 \mathrm{~b}$ on circulating and lesional $\mathrm{T}$ cells in patients with chronic plaque psoriasis," British Journal of Dermatology, vol. 155, no. 2, pp. 318-324, 2006.

[109] C. Fusco, F. R. Guerini, G. Nocera et al., "KIRs and their HLA ligands in remitting-relapsing multiple sclerosis," Journal of Neuroimmunology, vol. 229, no. 1-2, pp. 232-237, 2010.

[110] H. Qin, Z. Wang, W. Du et al., "Killer cell Ig-like receptor (KIR) 3DL1 down-regulation enhances inhibition of type 1 diabetes by autoantigen-specific regulatory T cells," Proceedings of the National Academy of Sciences of the United States of America, vol. 108, no. 5, pp. 2016-2021, 2011.

[111] S. W. Son, E.-O. Kim, E. S. Ryu et al., "Upregulation of Fas and downregulation of CD94/NKG2A inhibitory receptors on circulating natural killer cells in patients with new-onset psoriasis," The British Journal of Dermatology, vol. 161, no. 2, pp. 281-288, 2009. 


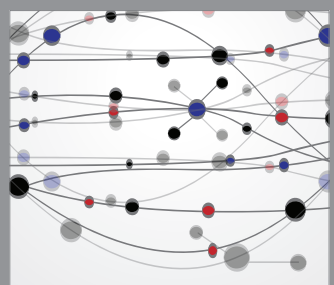

The Scientific World Journal
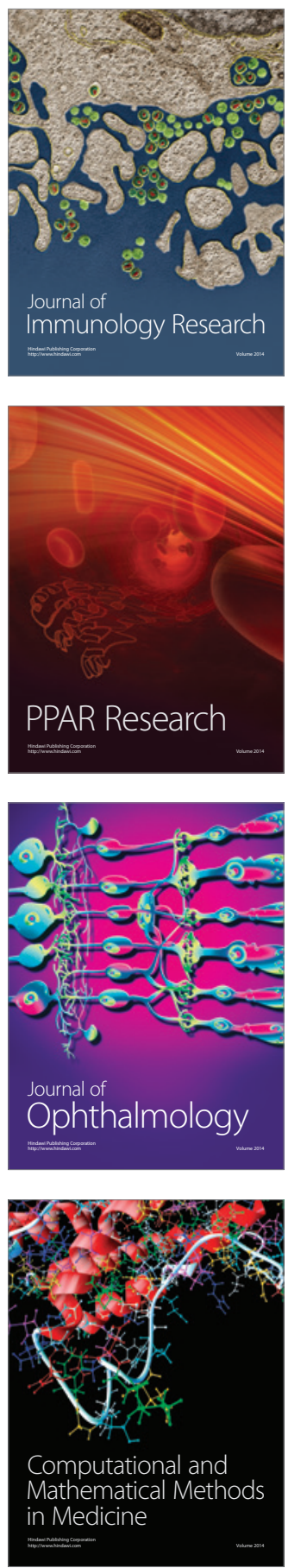

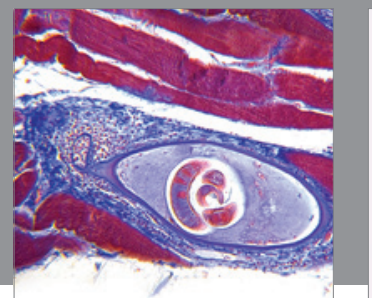

Gastroenterology

Research and Practice
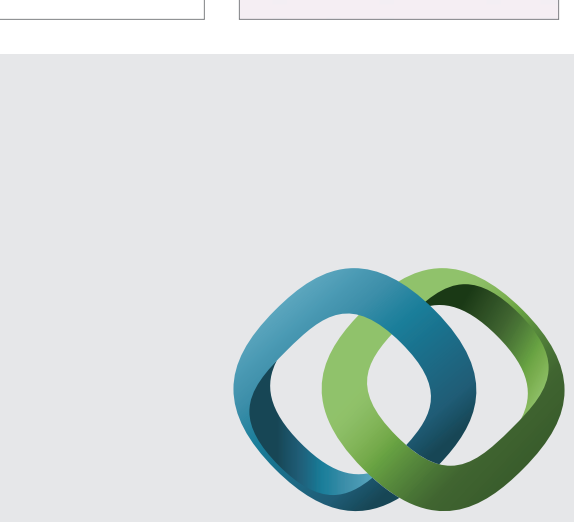

\section{Hindawi}

Submit your manuscripts at

http://www.hindawi.com
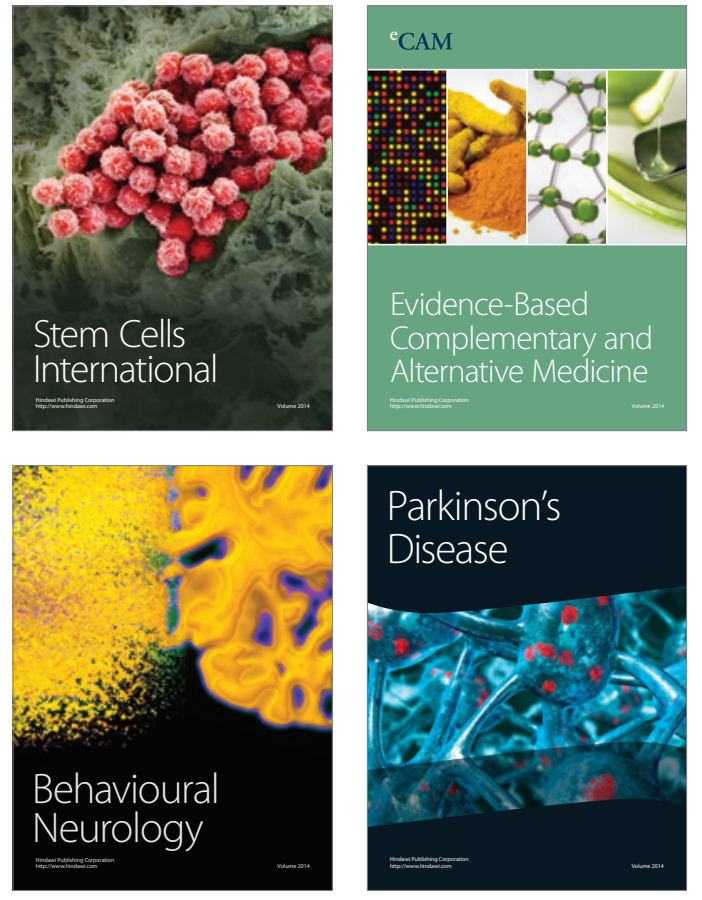
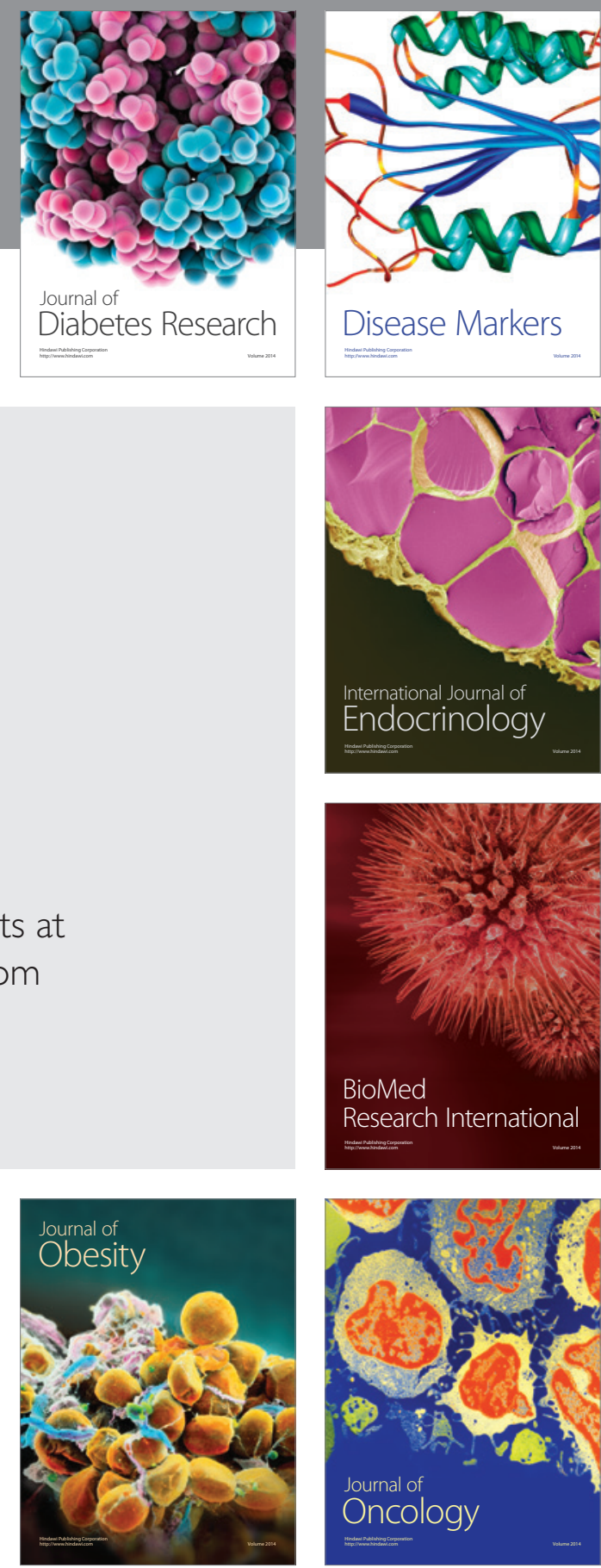

Disease Markers
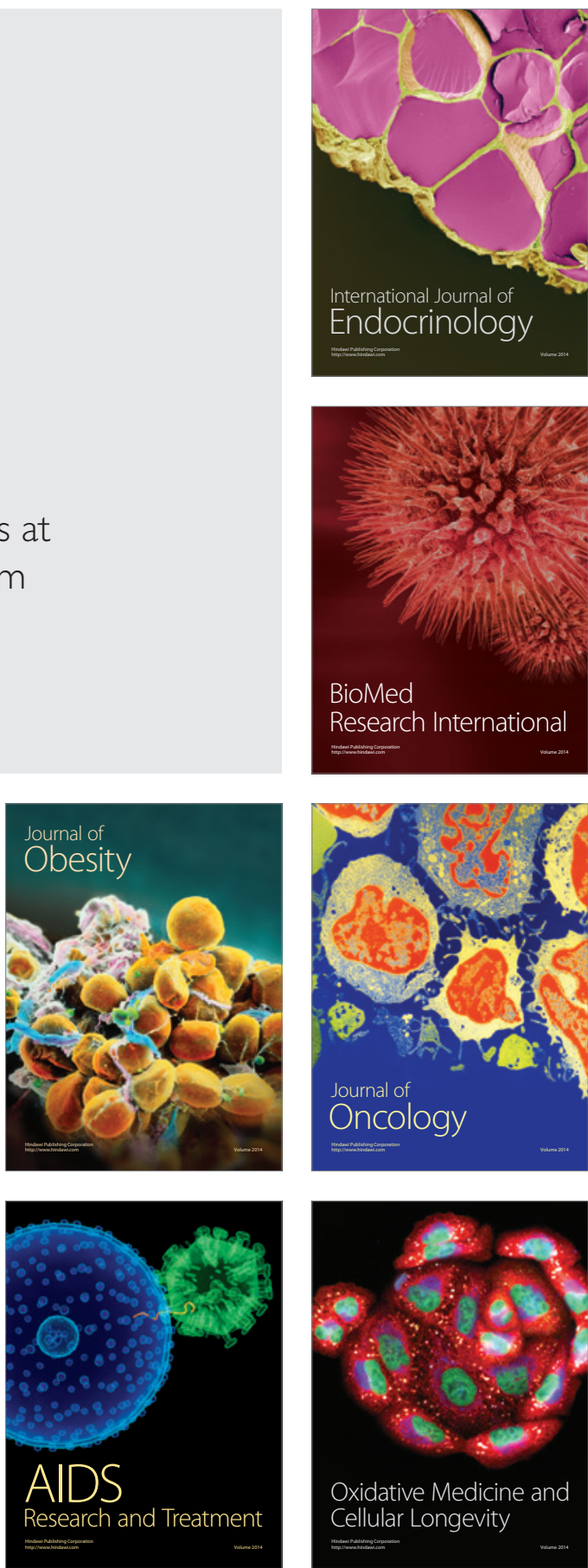